\title{
Australian consumers and carers versus pharmacy staff: do their priorities for pharmacy services align?
}

Sara S McMillan, ${ }^{1}$ Fiona Kelly, ${ }^{1,2}$ Adem Sav, ${ }^{1,5}$ Elizabeth Kendall, ${ }^{1}$ Michelle A King ${ }^{3}$ Jennifer A Whitty ${ }^{1,4}$ and Amanda J Wheeler. ${ }^{1,2}$

${ }^{1}$ Griffith Health Institute, Griffith University, University Drive, Meadowbrook, Queensland, 4131, Australia

${ }^{2}$ School of Pharmacy, Faculty of Medical and Health Sciences, University of Auckland, New Zealand

${ }^{3}$ School of Pharmacy, Griffith Health Institute, Griffith University, Gold Coast Campus, Parklands Drive, Southport, Queensland, 4215, Australia

${ }^{4}$ School of Pharmacy, University of Queensland, Cornwall Street, Wooloongabba, Queensland, 4102, Australia.

${ }^{5}$ School of Allied Health, Australian Catholic University, Banyo, Queensland, Australia.

\section{Corresponding Author}

Sara S McMillan

Population and Social Health Research Program, Griffith Health Institute, Room 2.15, Building L08, Griffith University, University drive, Meadowbrook, Australia, 4131

Telephone: +61 (0)7 33821571

Fax: +61 (0)7338 21041

Email: s.mcmillan@griffith.edu.au 


\section{Consumers and carers versus pharmacy staff: do their priorities for pharmacy services}

align?

\section{Abstract}

Background: Health professionals, including pharmacists, are encouraged to meet the needs of their consumers in an efficient and patient centred manner. Yet, there is limited information as to what consumers with chronic conditions need from pharmacy as a healthcare destination, or how well pharmacy staff understand these needs.

Objective: To identify service user priorities for ideal community pharmacy services for consumers with chronic conditions and carers, and compare these priorities with what pharmacy staff think they want.

Methods: The Nominal Group Technique was undertaken with pharmacist, pharmacy support staff, consumer and carer groups, in four Australian regions, between December 2012-April 2013. Participant ideas and priorities for ideal services or care were identified, and contextual insight was obtained by thematic analysis.

Results: Twenty-one nominal groups were conducted, including 15 consumer and carer, four pharmacist and two pharmacy support staff groups. Pharmacy staff views generally aligned with consumer priorities, such as access, affordability, patient centred care and continuity and coordinated care, yet diverged with respect to consumer information or education on medication and services. Fundamentally, consumers and carers sought streamlined access to information and medication, in a coordinated, patient centred approach. Alleviating financial burden was a key consumer priority, with a call for the continuation and extension of medication subsidies. 
Conclusion: Overall, pharmacy staff had a reasonable understanding of what consumers would prioritise, but further emphasis on the importance, delivery, or both, of consumer information, is needed. Greater consideration is needed from policy makers as to the financial barriers to accessing medication for consumers with chronic conditions.

\section{Key points for decision makers}

- Consumers highly valued information or education; it is imperative for pharmacy staff, especially pharmacists, to provide medication information, in a patient centred way.

- Financial burden is a key issue for medication users; further advocacy is needed to reduce barriers to medication access. 


\section{Introduction}

The burden associated with living with, managing, and treating chronic conditions, alongside the increasing prevalence of long term conditions, has led to countries proposing or initiating numerous health reforms. Health professionals are encouraged by governments and consumer groups to meet the needs of their consumers in an efficient and patient centred manner [1-3]. Pharmacists have not been excluded from this directive, particularly as people with chronic conditions are likely to be using medication, and hence, regularly visit a community pharmacy. The pharmacy profession has responded by providing recommendations on how pharmacists can provide further assistance in this area [4-7], such as pharmacist-led clinics in primary and hospital care [5], medication management programs [7], comprehensive disease management and repeat prescribing [4].

In Australia, since 1995, there has been an expansion of remunerated professional services via the Community Pharmacy Agreements; contracts between the Australian Federal Government and The Pharmacy Guild of Australia [8]. One example of a remunerated service is a medication use review, such as MedsCheck. This pharmaceutical care service involves a community pharmacist discussing a person's medication in a private consultation in the pharmacy [9]. Canadian pharmacies are also providing MedsCheck [4], and similar programs are available in the United Kingdom and New Zealand [10, 11]. However, one of the key issues in Australia is the ability to implement and sustain new professional services given the current pharmacy business model. Remuneration is primarily from dispensing and supply related services and history shows that many of these services are short-lived or curtailed. For example, there is a limit of ten MedsCheck services, per month, per pharmacy [12]. Even the existing Home Medication Review program, which was trialled in earlier agreements, has had funding cuts and service caps for cost-containment purposes [12]. Adding to this issue is that pharmacists are unable to be paid for providing clinical services other than medication 
reviews, outside of the pharmacy setting [12]. Numerous proposals and suggestions have been made, including remuneration for professional consultations [12], to providing chronic disease management such as undertaking prescribing [13] and expanding the continued dispensing initiative [14]. Recent legislation was introduced which allowed pharmacists in some Australian states and territories the ability to provide a one-off supply of a statin or the oral contraceptive pill, without a prescription, once a year [15].

Consequently, there has been a significant emphasis for pharmacists to be more effectively utilised to improve care for people with chronic conditions $[7,12,13,16]$. To achieve this, pharmacists must be well informed about the current experiences and needs of consumers with chronic conditions in an increasingly complex health system. In-depth knowledge about what patients prioritise from primary health services, such as pharmacy, will inform recommendations for new, extended or the continuation of pharmacy services that improve consumer experiences and outcomes.

The need to involve consumers in healthcare research is well recognised [17], particularly since adults with chronic conditions, especially co-morbidities, are more likely to report unmet healthcare needs [18]. For example, a recent Australian study identified that consumers with chronic conditions experienced financial hardship and valued continuity of care [19], which was verified by health professionals in a follow up study [20]. However, only consumers with specific conditions were included and the research was not specific to community pharmacy services [19]. A study exploring the service priorities of people, with a variety of chronic conditions or co-morbidities, and unpaid carers, is timely within the Australian pharmacy context.

Australia is a multicultural country. Two significant subgroups of this population are considered to be Aboriginal and Torres Strait Islander peoples culturally and linguistically diverse (CALD) and. People who 'identify as having specific cultural or linguistic affiliation' 
[21] are said to be CALD and Aboriginal and Torres Strait Islander peoples are the traditional owners of Australia. While studies have primarily explored the views of either group in relation to the overall health system [21-23], or specific aspects of pharmacy practice such as medication usage [24, 25], research has not taken an overarching view of these subgroups and their specific health needs in relation to pharmacy. It is therefore important to see if similar needs, such as more medication information [24], or the importance of interpreters or culturally competent bilingual health workers $[23,26]$ arise with respect to the pharmacy sector.

There are additional reasons why these two groups should be included in Australian pharmacy practice research. With respect to CALD groups, Komaric et al positioned that healthcare needs to be more responsive to their needs because Australia is becoming more culturally diverse [21]. Henderson and Kendall's research is driven by the low health service usage for many CALD groups [23, 26]. Aboriginal and Torres Strait Islander peoples made up 3\% of the Australian population in 2011 [27], yet have a higher risk of mortality from chronic conditions than other Australians [28].

The Australian Government has recognised the importance of improving the health and wellbeing of Aboriginal and Torres Strait peoples via a range of initiatives. The Closing The Gap (CTG) Pharmaceutical Benefits Scheme (PBS) co-payment measure [30] provides eligible Aboriginal and Torres Strait Islander consumers with subsidised or free medication [31]. In addition, the Quality Use of Medicines Maximised in Aboriginal and Torres Strait Islander peoples (QUMAX) program was continued in the current Community Pharmacy Agreement. In this initiative, participating Aboriginal Community Controlled Health Centres (ACCHS) and community pharmacies provide support for Aboriginal and Torres Strait Islander peoples who are non-adherent to their medication, and are subsequently at risk of ill 
health [32]. Furthermore, the program fosters collaboration between community pharmacies and the ACCHS, and aims to promote cultural awareness in the pharmacy setting [32].

This study aimed to identify 'what' consumers with chronic conditions prioritise, in terms of service provision from community pharmacy, both now and in the future. Further insight into the role/s for pharmacists could support additional funding and expansion of professional services. Given the evolution of community pharmacy practice, the study findings are an important addition to knowledge in this field. Finally, how well pharmacy staff, i.e. pharmacists and support staff, understand what their consumers would want from them in terms of service provision was also important to explore; any disparities would need to be addressed in order for pharmacy staff to provide optimal care. Subsequently, the study aimed to identify the priorities for ideal pharmacy services from the perspective of consumers with chronic conditions and carers, and compare their overall priorities with what pharmacy staff thought they wanted.

\section{Methods}

\subsection{Study design}

The nominal group technique was used to investigate priorities around ideal community pharmacy services. This approach has been used in pharmacy practice research [33, 34], and to explore differences in opinions, e.g. between consumers and pharmacy staff [35]. The nominal group technique offers a platform whereby participants are encouraged to share their ideas and vote on their priorities. A literature review was undertaken to explore the application of the nominal group technique and analysis process, thereby informing the development of a framework for facilitators [36]. Although the nominal group process can involve a number of stages, the core process involved: silent generation, round robin, clarification and voting/ranking (Table 1) [36]. For this research, participants were asked to 
prioritise five ideas of importance to them by allocating a score of 5 (most important) to 1 (least important). The sum of scores from each participant provided the first indication of group priorities.

Consumers and carers were asked to think about the following question: Imagine your local pharmacy several years into the future, what services could they offer to help you to meet your individual health goals? The question was informed by findings from previous interviews [37], research team discussions and further consultation with key healthcare stakeholders on an Advisory Panel. For example, it became evident during consumer and carer interviews that they didn’t know what they didn't know when considering what could be offered by community pharmacy. An appreciative inquiry approach was taken as this adopts a positive approach to problem solving [38]. Therefore, the question was formulated in a way to promote greater participant engagement and generate creative solutions. The research team modified an approach used by Bissell et al., who asked experts to consider the views of other stakeholders, in addition to their own perspectives [39]. Thus, pharmacy staff were asked the same question as consumers and carers, but were verbally directed to consider what their consumers would prioritise as ideal pharmacy services.

To adequately prepare participants, the research team used a pre-elicitation technique [38]. An information sheet outlining the current pharmacy services available in Australia (supplementary material 1) and an overview of the nominal group process, including the question, was provided to participants prior to conducting their group. This allowed participants the opportunity to reflect on their views beforehand. Two pilot groups were conducted in November-December 2012 to provide feedback on the information sheet, e.g. readability; and for the researchers to finalise the facilitator framework (Table 1), e.g. confirm timing of stages and the number of priorities that minimised participant burden. The 
pilot groups also provided the opportunity for the four facilitators to familiarise themselves with the nominal group technique [40].

\subsection{Participants}

Consumer participants were required to have a chronic condition or be an unpaid carer for someone that did (e.g. a family member), as well as live or access care in one of the following Australian regions: the urban regions of Perth (Western Australia) and LoganBeaudesert (Queensland), the semi-rural area of Northern Rivers (New South Wales), and the rural area of Mt Isa (Queensland). To help identify different views, separate groups were held consisting of pharmacists, other pharmacy staff, consumers and carers. Consumers were further stratified into Aboriginal and Torres Strait Islander peoples, and culturally and linguistically diverse groups.

A purposive and snowball sampling approach was used for recruitment [41], with assistance provided by community pharmacies, general practices and consumer organisations in the four study areas. Further project marketing occurred via newspaper advertisements and targeted recruitment at various locations, e.g. shopping centres and healthcare clinics. It was anticipated that 16 consumer and carer groups (four in each site), and six pharmacy staff groups would be needed to obtain a broad range of participants and ideas.

\subsection{Data collection}

Ethics approval was obtained from a University Ethics Committee. Three of the four facilitators had either a background in public health or pharmacy, and one was a consumer researcher; all facilitators had qualitative research experience. There were three facilitators for most groups: a primary facilitator, a scribe for the round-robin and clarification phases, and a note taker who recorded ideas electronically using Microsoft Office ${ }^{\circledR}$ Excel (v14) and 
calculated the final scores for the nominal group, i.e. the scores for each item were summed to identify the priority list.

Nominal groups were undertaken between December 2012 and April 2013, in numerous locations within the four project areas, including community and healthcare centres, universities and community pharmacies. Written and verbal consent was obtained prior to audio-recording sessions, which were then transcribed verbatim.

\subsection{Data analysis}

Both quantitative (original ideas and ranking scores) and qualitative (group transcripts) data were obtained from each group. Thematic analysis of the original group ideas (raw data) was undertaken by two researchers, and reviewed and discussed by two other researchers for reliability purposes. The thematic framework was validated by the entire research team, resulting in 12 over-arching themes (Table 2). These themes were then applied to the raw data, i.e. original group ideas, by four independent researchers, followed by a discussion for consensus purposes.

Two methods were undertaken for further data analysis purposes: to identify the overall priorities for the entire consumer, carer and pharmacy staff data-sets, as well as the top five priorities for each group for between-group comparisons. The first analysis process used a technique by Van Breda [42]; an average score for each theme was calculated by summing the average scores for the individual ideas within that theme and dividing it by the total number of ideas that appeared in the theme. Van Breda [42] then used the average scores for the themes and the frequency of themes, i.e. how many times a theme appeared in the top five and how often an idea was raised and coded under the same theme, to calculate a combined rank that provided an indication of the relative importance of the theme for the sample overall. The second analysis method was devised by the researchers, which was 
informed by the literature review [36]. Briefly, the total score (sum of points) for each theme identified by each group was calculated, resulting in a priority list. The relative importance score (\%) for each priority was then identified, reflecting the total value placed on a theme by the group. For example, patient-centred care as a theme scored 85 points from nominal group 3. This was divided by the maximum number of points that a theme could be allocated by group 3 participants, e.g. 14 participants x 15 points $(5+4+3+2+1)$, multiplied by 100 . This resulted in a relative importance score of 40.5 (Table 4, supplementary material 2). Detailed information on the analysis process are described elsewhere [36].

Using QSR NVIVO $9^{\odot}$, the qualitative data were coded according to the 12 overarching themes, thus providing further insight into the group priorities.

\section{Results}

Twenty-one nominal groups were conducted with 138 participants in 15 consumer and carer ( $n=103)$, four pharmacist $(n=22)$, and two pharmacy support staff groups $(n=13)$. Twelve groups were conducted in Perth and Logan-Beaudesert, four groups in Mt Isa and five in Northern Rivers. There was a range of two to fourteen participants per group, with an average of six or seven members. A variety of chronic conditions were experienced by consumers and carers, including, but not limited to, the: cardiovascular system, e.g. hypertension; malignant disease, e.g. cancer; endocrine disorders, e.g. diabetes; respiratory disorders, e.g. asthma; central nervous system, e.g. depression, back pain, epilepsy and Parkinson's disease; and musculoskeletal disorders, e.g. arthritis. A range of conditions were also identified that are less commonly researched when exploring chronic conditions, such as tetralogy of Fallot, Huntington’s disease and inclusion body myositis. 
The overall top five priorities for consumer and carer groups' ideal pharmacy services are presented (Table 3) and explored further in relation to individual group location and composition (Table 4, supplementary material). Results are compared to the views of pharmacy staff to identify how well they understood the priorities of this consumer group (Table 2).

Overall, information or education was the most highly valued pharmacy service for consumers and carers, with twelve groups nominating this theme in their top five priority list. However, pharmacy staff views did not align with this; they perceived that consumers would want innovative services such as medication continuance, e.g. repeat prescribing (Table 3). Otherwise, apart from slight differences in the ranking order of the top priorities, there was alignment in views for other themes.

\subsection{Consumer information or education}

Medication related information was a key focus for consumers and carers, with an emphasis on what medication is used for, how to use it, potential side effects, and treatment and monitoring updates. The importance of safeguarding against drug interactions and advising consumers of these was emphasised:

...I take so many [medications] I want to know that they're compatible with each other Aboriginal and Torres Strait Islander Consumer (Male, Perth).

Nine out of 15 consumer and carer groups sought further explanation about generic (bio-equivalent) medications, including how they differed from the original brand, who benefited most from their use, and the reason/s for price differences. Pharmacists agreed that generic confusion could be minimised by more consumer information:

I think that generics are still an issue so less confusion, more patient counselling. Pharmacist (Female, Perth). 
Consumers and carers wanted pharmacists to proactively and consistently offer verbal and written medication information, and spend time explaining this in a meaningful, patient centred way:

...if you need to use jargon explain what it is...you don't want to feel like you're being treated like you're stupid but at the same time... Consumer (Female, Perth).

Consumers and carers also sought greater awareness of the existence, or availability, of pharmacy services and medication entitlements.

Only pharmacists in the Northern Rivers area prioritised consumer information in their top five list. Both pharmacy support staff groups thought that consumers would want more time with the pharmacist, expressing a preference for taking on technical tasks to free up pharmacists to do this. Due to concerns over the training or qualifications of pharmacy support staff to provide counselling, consumer and carer groups preferred pharmacists to provide information. Pharmacy support staff suggested the use of badges to highlight their skills to consumers.

\subsection{Access}

There was a strong desire for continued or better access to quality medication, equipment and pharmacy services, with further discussion on the factors that influenced access, i.e. the pharmacy environment, and how to increase this access, i.e. longer opening hours. Ultimately, access was considered important to improve convenience and consequently, relieve some of the burden associated with managing a chronic condition/s or being a carer. Frustration was evident when medication was not in stock, resulting in multiple trips back to the pharmacy:

...they [pharmacy staff] should know that he's on it [the medication] and how long it's going to last and have it there. Consumer and Carer (Female, Mt Isa). 
Although there was an appreciation of the reasons why a pharmacy may not have adequate stock of medication, this was of little comfort to rural participants who, compared to their urban counterparts, could not visit another pharmacy as easily:

...better supply of medications in rural areas, because you don't have the choice you have in the city...Consumer (Female, Mt Isa).

Conversely, Mt Isa and Northern River pharmacists perceived that their clients would want greater access to pharmacy services, such as easier commissioning of the Home Medication Review $^{1}$ process and increased dispensing efficiency.

A pharmacy environment conducive to healthcare access was also important for consumers and carers, and further verified by pharmacy staff. This included a clean and comfortable environment, increased privacy, and time with the pharmacist, e.g. more or better utilisation of pharmacy staff and technology. Access to a pharmacist's advice online or via the phone was particularly convenient for people who had physical difficulty visiting a pharmacy:

...we should have like a Pharmacy direct, where you can actually ring and there are pharmacists manning phones constantly... Carer (Female, Perth).

Longer opening hours or a way to access medication outside of normal trading hours was also discussed by consumer and carers, particularly in the more rural/semi-rural areas of Mt Isa and Northern Rivers. Beyond increased access to the pharmacist, only half of the pharmacy staff groups believed their consumers would want extended opening hours or seven-day pharmacy trading.

\subsection{Affordability}

\footnotetext{
${ }^{1}$ An accredited pharmacist reviews a person's medication at their home, and reports back to the GP with any medication recommendations.
} 
Affordability was the top priority for three consumer groups and a top five priority in eleven groups, yet not considered as high a priority by pharmacy staff. Although consumers and carers were appreciative of Government initiatives to facilitate equitable medication access, affordability arose as their third (overall) priority. This appeared to be influenced by the cultural background or geographical location of participants. Ideas included free or further subsidised medication, devices, or services, more price consistencies between, and payment options in, community pharmacies.

Medication was deemed particularly expensive if a consumer was ineligible for Government subsidies; ${ }^{2}$ ultimately, consumers wanted employment but felt punished for working due to loss of subsidies. Some consumers experienced treatment delays as they could not afford their medication. Although pharmacy groups confirmed that consumers and carers would want cheaper or free medication, concerns were raised:

...if someone pays nothing for it they don't value it...Pharmacist (Female, Northern Rivers).

While pharmacies were acknowledged within the context of a business, urban participants wanted greater pricing consistency, and rural participants sought better cost alignment with urban areas. No annual increase to the Pharmaceutical Benefits Scheme Safety Net threshold ${ }^{3}$ was requested by some consumers and carers, with rural pharmacists verifying that some consumers who should be eligible, do not reach this threshold as they use various pharmacies and do not maintain an overall medication record.

Contrary to other groups, affordable medication was less of a priority for Aboriginal and Torres Strait Islander participants, which was attributable to the Closing the Gap

2 The Australian Government provides assistance for low income earners in the form of a concession card. This allows medication to be obtained at a cheaper price.

${ }^{3}$ Australian's who reach a certain threshold on medications are entitled to either reduced (copay), or free, medication supply, for the rest of the calendar year. 
initiative. ${ }^{4}$ Instead, these groups sought greater pharmacy staff awareness of Closing the Gap, and to offer consumer accounts or flexible payment systems, e.g. direct medication payments through Centrelink, an Australian Government welfare organisation:

...if you don't have any money for the medication they have those Centrepay forms that you can fill out and it comes out of your pay from Centrelink... Aboriginal and Torres Strait Islander Carer (Female, Mt Isa).

\subsection{Patient Centred Care}

Consumers and carers wanted care that encompassed friendly, approachable pharmacy staff who took time to listen, and provided personalised service that recognised and respected their individual needs. This was clearly an important component of any pharmacy service, which reflected a spectrum from personalised service through to care incorporating one or more attributes of patient centred care [43]. At a minimum, people wanted pharmacy staff to smile, be friendly, attentive, and know their names, but within a professional context.

In contrast, only one pharmacist and pharmacy support staff group believed their consumers would prioritise patient centred care. Nevertheless, their ideas did align with some consumer suggestions; providing care that was honest and trustworthy, effective communication and the development of a consumer-pharmacist relationship:

I think they'd like to see a pharmacist they know, someone that they've got a relationship with. Pharmacist (Female, Perth).

Respect was a collective need for consumers and carers when interacting with pharmacy staff. This included maintaining privacy and confidentiality, respecting brand or medication preferences and avoiding a patronising tone during counselling. Respectful care

\footnotetext{
${ }^{4}$ Aboriginal and Torres Strait Islanders who have a chronic condition/s may be eligible for subsidised, or free, medications.
} 
was emphasised by Aboriginal and Torres Strait Islander peoples, particularly within the context of anti-discrimination and “men's and women's business" [44], i.e. that gender specific healthcare is provided by someone of the same gender:

...having a man come up to me to talk about is really, is like a no. You don't do that...Disrespectful. Aboriginal and Torres Strait Islander Consumer (Female, Perth).

Culturally appropriate care was a high priority for Aboriginal and Torres Strait Islander peoples; patient centred care was the top priority for three of the four groups. While greater cultural awareness was important, two of the four Aboriginal and Torres Strait Islander groups also desired more of their own people to work in a pharmacy:

...you never, ever see an Aboriginal face working behind the counter in a pharmacy...it would be ideal for those chemists to employ an indigenous person who is culturally sensitive... Aboriginal and Torres Strait Islander Consumer (Male, Perth) Although patient centred care was less of a priority for culturally and linguistically diverse participants, they did express a desire for culturally appropriate care and good interpersonal communication skills. Use of interpreters was suggested to facilitate the transmission of information and education. Conversely, cultural awareness was not discussed among pharmacy staff groups as something they thought their clients would prioritise.

\subsection{Continuity and coordinated care}

This theme was emphasised by urban consumer and carer groups, with ideas including: colocation and coordination of services or health professionals, healthcare records and follow ups. Group differences were also identified, for example, healthcare records were predominantly discussed by Aboriginal and Torres Strait Islander and carer groups, compared to a referral/triage role by mixed consumer/carer groups. 
The co-location of health professionals was discussed by consumers and carers as involving either: a 'one stop shop' with all health professionals, pharmacy staff situated within the medical centre, or other health professionals working in the pharmacy. Perth pharmacy support staff thought consumers would want familiar faces in the pharmacy, as well as health professionals to be located there, e.g. online access to a GP, or co-located in a one stop shop:

I think they could have a one stop shop and literally go from door to door and see all their health professionals... Pharmacy support staff (Female, Perth).

The pharmacy was also viewed by some consumers as an ideal setting for someone, i.e. a pharmacist or other health professional, to provide individualised information, support and to refer them to other services:

Have links/info [information] to all my other health professionals, medications, complementary medications and other lifestyle choices, to enable the pharmacist and their assistants to offer me the best service and medications and referrals to my needs Consumer and Carer (Female, Logan-Beaudesert).

Extending the pharmacist's role to refer consumers directly to another health professional or service was also viewed by pharmacists as an aspect of continuity of care that consumers would want. Alternatively, a pharmacy support staff group discussed this in the form of a local information directory/portal accessible to consumers.

Consumers and carers desired the use of an electronic medication and health record, in the form of a chronic illness card/chip or a national online database, which they and their health providers could access. These records were described as having multiple purposes: to act as a portable record to streamline medication supply, provide individualised information, 
and prompt pharmacists to remind consumers when check-ups were due or if they were eligible for relevant pharmacy services:

...if you walk into another pharmacy, they just type in your name and everything comes up...So you don't have to constantly tell everyone the same story... Carer (Female, Perth).

Pharmacy staff believed that consumers would want streamlined care, with all pharmacist groups emphasising the importance of consistent healthcare records. Open dialogue, e.g. dynamic feedback between pharmacists and GPs regarding a consumer's progress, was also thought to be important to consumers:

...collaboration between the pharmacist and the patient's other healthcare professionals to improve their outcomes...the patient would feel like they had a whole team trying to work for them to improve their health... Pharmacist (Female, LoganBeaudesert).

\section{Discussion}

This study asked consumers with chronic conditions and their carers to propose and prioritise their ideas for ideal pharmacy services, and explored how well pharmacy staff understand what these consumers want. Fundamentally, consumers and carers sought streamlined access to information and medication, in a coordinated, patient centred manner. Overall, pharmacy staff had a reasonable understanding of what consumers would prioritise, such as access, affordability, patient centred care and continuity and coordinated care. These findings suggest that consumer needs and priorities generally fit within the services that community pharmacies currently offer. However, the pharmacy profession and community pharmacies need to carefully consider how these services could be improved, e.g. using electronic healthcare records to improve coordinated care and increasing the opportunities for 
pharmacists to talk to consumers. This latter point is particularly important given the emphasis placed on information or education and patient-centred care by consumers and carers.

Although consumers placed greater emphasis on information, only one pharmacist group included consumer information in their top five priorities. It is plausible that the other pharmacists perceived this subgroup of consumers to be 'experts' in managing their chronic conditions, and therefore, less likely to need information. Alternatively, pharmacists would strongly identify with this role given it is a professional practice standard [45], and may have considered counselling as something they routinely do as a non-negotiable aspect of any pharmacy service. Although rural pharmacists did not raise any specific ideas pertaining to information or education, ideas were related to improving healthcare access, aligning with the needs of a rural/remote context. These results underscore the importance of pharmacy staff optimising counselling procedures in their everyday practice. Furthermore, counselling is neglected in pharmacy payment models; pharmacists are not paid to provide information or education in the community pharmacy setting. Given that information or education was the top priority for consumers and carers, consideration is needed by the Australian Government as to how pharmacists can increase this service for people with chronic conditions and their carers.

Pharmacy support staff were more in-tune with consumer preferences than pharmacists, which reflects their key customer interaction role [46] as the first person that consumers usually speak to. Ultimately, information needs to be tailored to the specific needs of the consumer [47], in a manner that consumers understand and makes them feel 'safe' and respected. Consumers and carers also wanted pharmacists to be more proactive and consistent in offering medication information. While the need for a patient centred approach towards pharmacy counselling has been previously highlighted [48], more work is needed to optimise 
this. For example, increased tertiary training on interpersonal communication skills is recommended to assist pharmacists to develop consumer relationships [49].

Confusion over generic medications is a long established concern, and this study further confirms this issue. Pharmacy staff need to reduce this knowledge gap; optimising consumers' understanding of generics is likely to promote patient choice, medication safety, and some, if minimal, cost savings for them [50].

Patient centred care was the fourth priority overall for consumer and carer groups, and this supports calls for greater adoption of this approach in the pharmacy setting $[51,52]$. Only one pharmacist and one pharmacy support staff group voted this theme as a top five priority for consumers and carers. While this result could reflect an assumption that patient centred care is already part of pharmacy services, it would be in the best interest of pharmacies to look towards actively recruiting or training their workforce to address patient centred priorities. Also, research exploring the application of patient centred care within a pharmacy context is limited. While a recent systematic review proposed that having a relationship with one's clinician can result in a small, but statistically significant improvement in health outcomes [53], further research is needed to determine how patient centred care can be effectively implemented, particularly across different pharmacy settings, and the subsequent pharmacy and consumer outcomes.

Cultural awareness and respect was a particular focus for Aboriginal and Torres Strait Islander peoples. Strategies to improve care within the context of community pharmacy included enhanced multicultural training for pharmacy staff [25], and supporting opportunities for Aboriginal and Torres Strait Islander peoples to work in pharmacies [54]. While there is currently a Government funded program to promote cultural awareness and collaboration between pharmacies and Aboriginal Health Centres [32], the current study suggests that further uptake or promotion of this initiative is needed. However, cultural 
competency training may not be the sole answer, with Kendall and Barnett [55] suggesting that empathy needs to be supported and embedded throughout the health system, thus aligning with a patient-centred approach. Given the limited enrolments of Aboriginal and Torres Strait Islander peoples in vocational and university based pharmacy programs in previous years [56], and the call for more Aboriginal and Torres Strait Islander pharmacists to optimise care for their people [57], the continuation and expansion of programs supporting Aboriginal and Torres Strait Islander peoples to enter the pharmacy workforce is relevant [44, 57] This is even more important when, compared to other Australians, Aboriginal and Torres Strait Islander people have poorer health outcomes [58].

This study clearly identified that affordability is still a key concern of consumers with a chronic condition/s and their carers, particularly for those ineligible for Government subsidies. This strengthens the finding of substantial financial burden for this group of people [59]. Pharmacy staff appeared to have some understanding of financial burden for these consumers, with agreement that they would want 'cheaper' or 'free' medication. Unfortunately, the Australian Government's 2014 budget proposals indicate that Pharmaceutical Benefit Scheme threshold prices, i.e. medication co-payments, and Safety Net thresholds for consumers are set to rise [60]. Cost impacts on medication adherence [61]: increased medication co-payments result in reduced medication utilisation and thus, nonadherence [62, 63], and full medication subsidy increases adherence [64]. It is concerning that this population, who need medication the most, may experience delays in treatment because of financial burden. Although Pharmaceutical Benefits Scheme co-payment charges and Safety Net thresholds are controlled by the Australian Government, the pharmacy profession can still advocate for the removal of barriers to medication access, such as price increases. At a grass-roots level, community pharmacy staff should also raise awareness of the Safety Net Scheme to ensure that all eligible consumers can access cheaper medication; 
and consider providing additional payment options as discussed by consumer and carer groups, e.g. payment plans or direct payment from welfare agencies. Furthermore, medication prices can vary between pharmacies for private prescriptions and medication under the Pharmaceutical Benefits Scheme threshold; further discussion of fixed medication pricing may be warranted [59].

The rollout of patient controlled electronic health records is continuing, and the use of information and technology has been identified as a key enabler for pharmacists' extended roles [13]. Community pharmacists should consider utilising this technology as it has the potential to address consumer and carer needs, i.e. streamlined care. Consumers and carers also identified the community pharmacy as a plausible setting for care coordination to occur. Subsequently, the concept of the community pharmacy becoming a health hub destination [65] becomes more tangible.

\section{Limitations}

This study focused on consumers who have a chronic condition or are carers, a subgroup of the Australian population. The extent to which they can be generalised to other groups, for example to other health jurisdictions, is an empirical question, and the findings are not generalisable to other pharmacy consumers, i.e. those without a chronic condition. Researchers re-coded the original nominal group ideas to themes to allow for group comparisons, which may have limited the generalisabilty of the findings. However, bias was limited through research validation, quality checking and use of a consumer researcher. By agreeing to participate, both consumers and pharmacy staff were likely to be proactive and interested in healthcare improvements, thus potentially influencing their responses. Furthermore, the researchers did not assess participants’ level of health literacy. However, 
these participants were regular health service users, and thus their viewpoints are particularly relevant. While only four areas were included in the study sample, these were diverse in nature and comprised rural and urban living. One nominal group had only two participants, however, these results were included as they provided valuable insights. The researchers only conducted 21 of the 22 anticipated nominal groups; this was due to budgetary and time constraints. However, we do not believe this significantly impacts on the study findings, particularly when this is one of the largest studies using the nominal group technique. Apart from cultural diversity and geographical location, the results were not analysed with respect to other participant demographics, e.g. age, chronic condition/s, medication usage, or, for pharmacy staff, work employment history. It is plausible that these other factors influenced what participants considered to be important with respect to ideal pharmacy services. Finally, pharmacy staff were asked to consider what they thought their clients would prioritise in terms of pharmacy services; it is possible that some of their own ideas reflected what they wanted as a health professional.

\section{Conclusion}

Pharmacy staff generally understood consumer and carer needs. However, consumers valued information or education the most; a theme lacking from pharmacy staff responses. It is imperative for pharmacy staff, especially pharmacists, to provide medication information, in a patient centred way. Financial burden emerged as a key issue for medication users, in contrast with Australian Government intentions to increase medication costs. Therefore, policy makers need to pay greater attention to the financial barriers to medication access for consumers with chronic conditions and their carers.

\section{Conflict of interest}

None. 


\section{Funding}

This project is funded by the Australian Government Department of Health as part of the Fifth Community Pharmacy Agreement Research and Development Programme managed by The Pharmacy Guild of Australia. The financial assistance provided must not be taken as endorsement of the contents of this study.

\section{Contributors}

FK, EK, MK, JW and AJW participated in the design of the main study, SM, AS and FK were involved in designing and facilitating the nominal groups, as well as analysing the data. All authors validated the thematic framework used for data analysis. EK and AJW provided feedback on the analysis method. SM drafted the manuscript and all authors provided editorial comments. All authors read and approved the final manuscript. SM is guarantor of the overall manuscript.

\section{Acknowledgements}

A sincere thanks to all nominal group participants, as well as Beth Hunter, Rhonda Knights, Claire Campbell, and local champions who helped us to organise each group session. The researchers are also appreciative to the reviewers for their feedback. 


\section{References}

1. Australian Commission on Safety and Quality in Health Care. Patient-centred care: Improving quality and safety through partnerships with patients and consumers. Sydney; 2011.

2. International alliance of patients organizations. Declaration on patient-centred health care. International alliance of patients organizations. 2006. http://www.patientsorganizations.org/pchreview Accessed 14 July 2014.

3. Department of Health. NHS Patient Experience Framework. Department of Health, United Kingdom.

2012.

https://www.gov.uk/government/uploads/system/uploads/attachment_data/file/215159/dh_13 2788.pdf Accessed 14 July 2014.

4. Canadian Association of Chain Drug Stores. 9000 points of care: Improving Access to Affordable Healthcare. 2013. http://9000pointsofcare.ca/ Accessed 7 July 2014.

5. Smith J, Picton C, Dayan M. Now or Never: Shaping Pharmacy for the Future. London, England 2013.

6. Giberson S, Yoder S, Lee MP. Improving Patient and Health System Outcomes through Advanced Pharmacy Practice. A Report to the US Surgeon General: Office of the Chief Pharmacist, US Public Health Service 2011.

7. Pharmaceutical Society of Australia. Australians stay healthier: PSA's call to action on chronic disease. Canberra, ACT; 2013.

8. Australian Department of Health and Ageing. Pharmacy: Previous Community Pharmacy Agreements. Australian Department of Health and Ageing. 2011. http://www.health.gov.au/internet/main/publishing.nsf/Content/previous-community-

pharmacy-agreements Accessed 12 June 2013.

9. Australian Government Department of Human Services. Home Medicines Review (HMR). Medicare. 2012. http://www.medicareaustralia.gov.au/provider/pbs/fourthagreement/hmr.jsp Accessed 3 October 2012

10. Community Pharmacy Scotland. NHS Care Services: Chronic Medication Service. 2012.

http://www.communitypharmacyscotland.org.uk/nhs_care_services/chronic medication_serv ice/what is the chronic_medication_service.asp Accessed

11. TAS. About the Community Pharmacy Long Term Conditions Service. Central TAS. 2008.

http://www.centraltas.co.nz/CommunityPharmacyProgramme/LTCServicePHAMSException alCircumstances/tabid/331/Default.aspx Accessed 29 July 2014.

12. Pharmaceutical Society of Australia. Better health outcomes through improved primary care: Optimising pharmacy's contribution; 2014.

13. Building Upon Pharmacists' Practice In Australia: A vision for the profession; 2014.

14. Legislative Council Legal and Social Issues Legislation Committee. Inquiry into Community Pharmacy in Victoria. Victoria; 2014.

15. Pharmaceutical Society of Australia. Guidelines for the Continued Dispensing of eligible prescribed medicines by pharmacists. Pharmaceutical Society of Australia. 2012. http://www.psa.org.au/download/guidelines/medication-management/continued-dispensingpractice-guide.pdf Accessed

16. S Duckett, P Breadon, L Ginnivan. Access all areas: new solutions for GP shortages in rural Australia. Melbourne: Grattan Institute; 2013.

17. Shea B, Santesso N, Qualman A, Heiberg T, Leong A, Judd M, et al. Consumerdriven health care: Building partnerships in research. Health Expect. 2005;8(4):352-9. 
18. Ronksley PE, Sanmartin C, Quan H, Ravani P, Tonelli M, Manns B, et al. Association between chronic conditions and perceived unmet health care needs. Open Med. 2012;6(2):e48-58.

19. Jeon Y, Jowsey T, Yen L, Glasgow NJ, Essue B, Kljakovic M, et al. Achieving a balanced life in the face of chronic illness. Aust J Prim Health. 2010;16(1):66-74.

20. Yen L, Gillespie J, Rn YH, Kljakovic M, Anne Brien J, Jan S, et al. Health professionals, patients and chronic illness policy: a qualitative study. Health Expect. 2011;14(1):10-20.

21. Komaric N, Bedford S, van Driel ML. Two sides of the coin: patient and provider perceptions of health care delivery to patients from culturally and linguistically diverse backgrounds. BMC Health Serv Res. 2012;12:322.

22. Kendall E, Barnett L. Principles for the development of Aboriginal health interventions: culturally appropriate methods through systemic empathy. Ethnicity \& health. 2014 Jul 4:1-16.

23. Henderson S, Kendall E. Culturally and linguistically diverse peoples' knowledge of accessibility and utilisation of health services: exploring the need for improvement in health service delivery. Aust J Prim Health. 2011;17(2):195-201.

24. Swain L, Barclay L. They've given me that many tablets, I'm bushed. I don't know where I'm going: Aboriginal and Torres Strait Islander peoples' experiences with medicines. The Australian journal of rural health. 2013 Aug;21(4):216-9.

25. Hamrosi K, Taylor S.J, Aslani P. Issues with prescribed medications in Aboriginal communities: Aboriginal health workers' perspectives. Rural and remote health. 2006;6(2):557.

26. Henderson S, Kendall E, See L. The effectiveness of culturally appropriate interventions to manage or prevent chronic disease in culturally and linguistically diverse communities: a systematic literature review. Health Soc Care Community. 2011;19(3):22549.

27. Australian Bureau of Statistics. 3238.0.55.001 - Estimates of Aboriginal and Torres $\begin{array}{lllll}\text { Strait Islander } & \text { Australians, } & \text { June } & 2011 . & \end{array}$ http://www.abs.gov.au/ausstats/abs@.nsf/mf/3238.0.55.001 Accessed Feb 112014.

28. Australian Institute of Health and Welfare. Australia's Health 2014 - In Brief; 2014.

29. Council of Australian Governments. National Indigenous Reform Agreement. 2012. http://www.federalfinancialrelations.gov.au/content/npa/health_indigenous/indigenousreform/national-agreement_sept_12.pdf Accessed 11 Februrary 2014.

30. Australian Government Department of Health and Ageing. Closing the Gap: Indigenous Chronic Disease Package PBS Co-Payment Measure Pharmacy Staff Resource Booklet. ACT; 2010.

31. Australian Government Department of Human Services. Closing the Gap - PBS copayment measure.

2013. https://www.medicareaustralia.gov.au/provider/pbs/prescriber/closing-the-gap.jsp Accessed 11 February 2014.

32. Australian Government Department of Health and Ageing, The Pharmacy Guild of Australia, National Aboriginal Community Controlled Health Organisation. Quality Use of Medicines maximised for Aboriginal and Torres Strait Islander People (QUMAX). 2013. http://www.5cpa.com.au/docs/librariesprovider5/public-documents/initiatives-and-

programs/atsip/QUMAX/qumax-program-specific-guidelines.pdf?sfvrsn=0 Accessed 11 Feb 2014.

33. Tully M, Cantrill J. The use of the Nominal Group technique in pharmacy practice research: processes and practicalities. J Soc Admin Pharm. 1997;14(2):93-104. 
34. Bradley F, Schafheutle EI, Willis SC, Noyce PR. Changes to supervision in community pharmacy: pharmacist and pharmacy support staff views. Health Soc Care Community. 2013 Nov;21(6):644-54.

35. Hutchings HA, Rapport FL, Wright S, Doel MA, Wainwright P. Obtaining consensus regarding patient-centred professionalism in community pharmacy: nominal group work activity with professionals, stakeholders and members of the public. Int $\mathrm{J}$ Pharm Pract. 2010;18(3):149-58.

36. McMillan S.S, Kelly F, Sav A, Kendall E, King M.A, Whitty J.A, et al. Using the Nominal Group Technique: How to analyse across multiple groups. Health Serv Outcomes Res Method. 2014;14:92-108.

37. McMillan SS, Kelly F, Sav A, King M.A, Whitty J.A, Wheeler A.J. Consumer and carer views of Australian community pharmacy practice: awareness, experiences and expectations. J Pharm Health Serv Res. 2014;5(1):29-36.

38. Gonzales CK, Leroy G. Eliciting used requirements using Appreciative inquiry. Empir Software Eng. 2011;16:733-72.

39. Bissell P, Ward PR, Noyce PR. Appropriateness measurement: application to advicegiving in community pharmacies. Soc Sci Med. 2000;51(3):343-59.

40. McMillan S.S., Kelly F, Sav A, Kendall E, King M.A., Whitty J.A., et al. Using the Nominal Group Technique: How to analyse across multiple groups. J Health Serv Res Policy. 2013;[accepted 11 July 2014].

41. Liamputtong P. Research methods in health: foundations for evidence-based practice. Sydney, NSW: Oxford University Press; 2010.

42. Van Breda A.D. Steps to analysing multiple-group NGT data. The Social Work Practitioner-Researcher. 2005;17(1):1-14.

43. Morgan S, Yoder LH. A concept analysis of person-centered care. J Holistic Nurs. 2012;30(1):6-15.

44. Pharmaceutical Society of Australia. Guide to providing pharmacy services to Aboriginal and Torres Strait Islander people; 2014.

45. The Pharmaceutical Society of Australia. Professional Practice Standards - Version 4 - June 2010. Pharmaceutical Society of Australia. 2010. http://www.psa.org.au/download/standards/professional-practice-standards-v4.pdf Accessed 7 July 2014.

46. Braund R, Chesney KM, Keast EP, Ng LJ, Qi S, Samaranayaka S, et al. Are all pharmacy staff interested in potential future roles? Int J Pharm Prac. 2012;20(6):417-21.

47. Hamrosi KK, Aslani P, Raynor DK. Beyond needs and expectations: identifying the barriers and facilitators to written medicine information provision and use in Australia. Health Expect. 2014;17(2):220-31.

48. Shah B, Chewning B. Conceptualizing and measuring pharmacist-patient communication: a review of published studies. Res Social Adm Pharm. 2006;2(2):153-85.

49. Simmons-Yon A, Roth MT, Vu M, Kavalieratos D, Weinberger M, Rao JK. Understanding pharmacists' experiences with advice-giving in the community pharmacy setting: A focus group study. Patient Educ Couns 2012;89(3):476-83.

50. Chong CP, March G, Clark A, Gilbert A, Hassali MA, Bahari MB. A nationwide study on generic medicines substitution practices of Australian community pharmacists and patient acceptance. Health Policy. 2011;99(2):139-48.

51. Mey A, Knox K, Kelly F, Davey AK, Fowler J, Hattingh L, et al. Trust and safe spaces: mental health consumers' and carers' relationships with community pharmacy staff. Patient. 2013;6(4):281-9. 
52. McMillan S.S, Sav A, Kelly F, King M.A, Whitty J.A, Wheeler A.J. How to attract them and keep them: the pharmacy attributes that matter to Australian residents with chronic conditions. Int J Pharm Prac. 2013;22(4):238-45.

53. Kelley JM, Kraft-Todd G, Schapira L, Kossowsky J, Riess H. The influence of the patient-clinician relationship on healthcare outcomes: a systematic review and meta-analysis of randomized controlled trials. PloS one. 2014;9(4):e94207.

54. Swain L. Pharmacy Assistant School-based Traineeships for Aboriginal Students. Australian Pharmacist. 2010;29(10):814.

55. Kendall E, Barnett L. Principles for the development of Aboriginal health interventions: culturally appropriate methods through systemic empathy. Ethnicity \& health. 2014/07/06 ed; 2014. p. 1-16.

56. Australian Institure of Health and Welfare. Aboriginal and Torres Strait Islander Health Performance Framework 2012. Canberra: Australian Institute of Health and Welfare,; 2013.

57. Australian Government Department of Health, The Pharmacy Guild of Australia. Aboriginal \& Torres Strait Islander Pharmacy Scholarship Program. 5CPA. 2014. http://5cpa.com.au/programs/aboriginal-and-torres-strait-islander-initiatives/aboriginal-torresstrait-islander-pharmacy-scholarship-program/ Accessed 15 May 2014.

58. Australian Institute of Health and Welfare. Australia's health 2012. Australia's health no. 13. Cat. no. AUS 156. Canberra Australian Institute of Health and Welfare, ; 2012.

59. Whitty JA, Sav A, Kelly F, King MA, McMillan SS, Kendall E, et al. Chronic conditions, financial burden and pharmaceutical pricing: insights from Australian consumers. Australian health review : a publication of the Australian Hospital Association. 2014/08/08 ed; 2014.

60. Moffat C. Increased PBS co-payment to place pressure on pharmacy. Pharmacy News. 2014. http://www.pharmacynews.com.au/news/latest-news/increased-pbs-co-paymentto-place-pressure-on-phar Accessed 14 May 2014.

61. Briesacher BA, Gurwitz JH, Soumerai SB. Patients at-risk for cost-related medication nonadherence: a review of the literature. J Gen Intern Med 2007;22(6):864-71.

62. Hynd A, Roughead EE, Preen DB, Glover J, Bulsara M, Semmens J. Increased patient co-payments and changes in PBS-subsidised prescription medicines dispensed in Western Australia. Aust N Z J Public Health 2009;33(3):246-52.

63. Norris PT, Horsburgh S, Cumming J, Tordoff J. Prescription charge increases in New Zealand penalise the poor and sick. J Prim Health Care. 2014;6(1):4-5.

64. Choudhry NK, Bykov K, Shrank WH, Toscano M, Rawlins WS, Reisman L, et al. Eliminating medication copayments reduces disparities in cardiovascular care. Health affairs (Project Hope). 2014;33(5):863-70.

65. McMillan S.S, Wheeler A.J, Sav A, King M.A, Whitty J.A, Kendall E, et al. Community pharmacy in Australia: the health hub destination of the future. Res Soc Admin Pharm 2013;9(6):863-75. 
Table 1: Nominal Group framework for facilitators

Stages

Introduction

Initial

brainstorm

Silent generation

Round Robin

Clarification

Voting/

Ranking

Discussion
To provide an overview of the study and objectives of the group.

10

Confirm/obtain participant consent.

Participants are asked the following question: What would you describe as your most positive experience with a health care service or from seeking care within the Australian healthcare system? Sets the scene and facilitate discussion about the positive aspects of healthcare experiences that can be translated into future solutions.

Participants are instructed to record as many ideas down as possible in silence in response to this question: Imagine your local pharmacy several years into the future, what services could they offer to help you to meet your individual health goals?

Each participant presents one idea, this continues until ideas are exhausted. This is recorded on a whiteboard.

An opportunity to clarify/elaborate ideas on the board. Items checked for duplication and possible grouping.

Participants select their top FIVE preferences and then rank them (i.e. $5=$ most important item, $1=$ least important). 
Table 2: Overarching themes from nominal groups

\begin{tabular}{|c|c|c|}
\hline Theme & Explanation & Sub-themes \\
\hline Access & $\begin{array}{l}\text { Accessing care, e.g. } 24 \text { hour access, } \\
\text { limited access. }\end{array}$ & $\begin{array}{l}\text { Environment: that care is delivered in, } \\
\text { e.g. physical space of the pharmacy. }\end{array}$ \\
\hline Affordability & $\begin{array}{l}\text { Costs or affordability of care, free or } \\
\text { consistent or subsidised medication etc. }\end{array}$ & $\begin{array}{l}\text { Medication. } \\
\text { Devices. }\end{array}$ \\
\hline $\begin{array}{l}\text { Consumer } \\
\text { education/ } \\
\text { information }\end{array}$ & $\begin{array}{l}\text { Providing the consumer more information, } \\
\text { e.g. medication or services information. }\end{array}$ & $\begin{array}{l}\text { Pharmacy Marketing: of the } \\
\text { pharmacists' roles and services they } \\
\text { offer to the community. }\end{array}$ \\
\hline $\begin{array}{l}\text { Continuity } \\
\text { and } \\
\text { co-ordination } \\
\text { of care }\end{array}$ & $\begin{array}{l}\text { Ongoing care, relationships and } \\
\text { communication between health } \\
\text { professionals, or health professionals and } \\
\text { consumers. }\end{array}$ & $\begin{array}{l}\text { One-stop shop: Having all health } \\
\text { professionals or services in one centre. } \\
\text { Healthcare records: References to use } \\
\text { or access to healthcare records, e.g. e- } \\
\text { health. }\end{array}$ \\
\hline $\begin{array}{l}\text { Quality } \\
\text { service } \\
\text { delivery }\end{array}$ & $\begin{array}{l}\text { Providing a quality service, following or } \\
\text { improving professional standards, duty of } \\
\text { care etc. }\end{array}$ & $\begin{array}{l}\text { Healthcare professional competency. } \\
\text { Quality assurance and improvement: } \\
\text { Improving the availability and delivery } \\
\text { of services beyond staff training, e.g. } \\
\text { larger medication labels. }\end{array}$ \\
\hline $\begin{array}{l}\text { Innovative } \\
\text { services/roles }\end{array}$ & $\begin{array}{l}\text { New pharmacy services or pharmacist } \\
\text { roles in Australia. }\end{array}$ & $\begin{array}{l}\text { Services e.g. drive thru. } \\
\text { Roles e.g. repeat prescribing. }\end{array}$ \\
\hline $\begin{array}{l}\text { Health } \\
\text { promotion }\end{array}$ & $\begin{array}{l}\text { Preventative health and health promotion, } \\
\text { e.g. lifestyle or non-medication related } \\
\text { services such as smoking cessation or } \\
\text { walking groups. }\end{array}$ & $\begin{array}{l}\text { Screening and monitoring: diagnostic } \\
\text { tests to check patient progress, e.g. } \\
\text { blood pressure, blood glucose. }\end{array}$ \\
\hline $\begin{array}{l}\text { Medication } \\
\text { management }\end{array}$ & $\begin{array}{l}\text { Pharmacy staff assisting consumers to } \\
\text { manage their medications, e.g. dose } \\
\text { administration aids, medicine use reviews. }\end{array}$ & \\
\hline $\begin{array}{l}\text { Patient } \\
\text { centred care }\end{array}$ & $\begin{array}{l}\text { References to or lack of the four attributes } \\
\text { of patient centred care, e.g. empowering, } \\
\text { holistic, respectful and individualised care. }\end{array}$ & $\begin{array}{l}\text { Interpersonal relationships: interactions } \\
\text { that consumers desire with healthcare } \\
\text { professional. } \\
\text { Gender awareness: respecting gender- } \\
\text { specific needs. } \\
\text { Culturally appropriate: services, e.g. } \\
\text { use of interpreters, cultural awareness. }\end{array}$ \\
\hline $\begin{array}{l}\text { Supply } \\
\text { related service }\end{array}$ & $\begin{array}{l}\text { Non-innovative services related to } \\
\text { medicine supply, e.g. home delivery. }\end{array}$ & Labelling and repeats: e.g. usability. \\
\hline $\begin{array}{l}\text { Government } \\
\text { initiative/ } \\
\text { legislative } \\
\text { changes }\end{array}$ & $\begin{array}{l}\text { Macro-level changes within the health } \\
\text { system and changes within the pharmacy } \\
\text { setting. }\end{array}$ & \\
\hline Carer & Their needs, experiences etc. & \\
\hline
\end{tabular}


Table 3: Top five priorities for consumer and carer and pharmacy staff groups

\begin{tabular}{lccccc}
\hline & $\begin{array}{c}\text { Final Rank } \\
\text { (Overall } \\
\text { Priority) }\end{array}$ & $\begin{array}{c}\text { Frequency the } \\
\text { theme was in the } \\
\text { top priority list } \\
\text { (for all groups) }\end{array}$ & $\begin{array}{c}\text { Frequency the theme } \\
\text { was the top priority } \\
\text { (for all groups) }\end{array}$ \\
\hline Consumers, carers or both (n=15) & & $\mathbf{( n )}$ & $\mathbf{( \% )}$ & $\mathbf{( n )}$ & $\mathbf{( \% )}$ \\
\hline Consumer information or education & 26.50 & 12 & 80.0 & 1 & 6.7 \\
Access & 25.50 & 10 & 66.7 & 2 & 13.3 \\
Affordability & 25.00 & 11 & 73.3 & 3 & 20.0 \\
Patient centred care & 24.50 & 8 & 53.3 & 3 & 20.0 \\
Continuity/coordinated care & 24.00 & 9 & 60.0 & 2 & 13.3 \\
\hline Pharmacy staff (n=6) & & $\mathbf{( n )}$ & $\mathbf{( \% )}$ & $\mathbf{( n )}$ & $\mathbf{( \% )}$ \\
\hline Innovative services and roles & 27.00 & 6 & 100.0 & 2 & 33.3 \\
Continuity/coordinated care & 26.00 & 4 & 66.7 & 1 & 16.7 \\
Access & 23.00 & 5 & 83.3 & 2 & 33.3 \\
Affordability & 22.00 & 4 & 66.7 & 0 & 0 \\
Patient centred care & 18.00 & 2 & 33.3 & 1 & 16.7 \\
\hline
\end{tabular}


Supplementary material 1: Consumer information sheet outlining current Australian pharmacy services

Ongoing (chronic and long term) health conditions (e.g. asthma, diabetes) can have a significant impact on the people who experience them, on those who care for them (carers) and on other family members. This impact can include the negative effect of symptoms like pain or restriction of daily activities, or the workload created by the treatment(s) that are required to manage these conditions (e.g. multiple medical appointments, medication side effects). This impact is also known as 'treatment burden' and can include the time taken to do the daily tasks that must be performed by people in order to monitor their illness, the financial burden of treatment, or the burden associated with accessing and using healthcare services (e.g. hospital waiting lists).

When changes are made to improve healthcare, people who use healthcare are not always consulted about what is important to them. People want their concerns to be heard. They want their healthcare experiences and priorities to be valued. People value caring healthcare professionals, who take time to listen to their patients, get to know them, treat them as an individual, consider their overall situation as well as their specific health condition(s) and respect their opinions.

One healthcare professional who can offer a range of healthcare services is your local pharmacist. However, pharmacies are often only used to purchase medicines. Your local (community) pharmacy has trained health professionals (pharmacists and assistants) who can provide advice or healthcare services whenever you need them. In the last ten years, pharmacies have offered new services in addition to medication supply, and the profession is looking to extend its role(s) in the future. Although not all pharmacies offer all of these services, they might offer some of the services below

\section{Standard Services}

Services that most pharmacies offer

- Medication supply: Medication on prescription, without prescription, herbal medication, home deliveries. Pharmacists check medication safety before supply, provide medication and health care advice.

- Medication returns: Unwanted medication can also be returned to the pharmacy.

-Dose Administration Aids (e.g. Webster -pak $\left.{ }^{\circledR}\right)$ : Condensing medication(s) into a weekly pack.

- Home Medication Reviews: A specially trained pharmacist will discuss all of your medications and medication needs with you at home to ensure that you get optimal, safe and effective use of medication(s).

- Additional services or programs: Some pharmacies offer advice/programs for diabetes, weight management, smoking cessation, opioid cessation, health checks and immunisations.

\section{New Services}

\section{Services that some pharmacies offer}

-Health promotion: Improve health care awareness via information to prevent ongoing health conditions.

- Screening and risk assessment: Identify people undiagnosed and raise awareness of risk factors.

-Condition monitoring: Provide monitoring, information and self-management advice.

- MedsCheck: A pharmacist will discuss all of your medications and health goals in the pharmacy. There is also a similar service for Type 2 diabetes (Diabetes MedsCheck).

-Please note that these services are often for ongoing health conditions like diabetes, mental health, etc.

\section{Future Services}

\section{Potential role(s) for Australian pharmacists in the future}

-Continuing medicine supply: Trained pharmacists continue a person's normal medications (i.e. provide repeat prescriptions).

- Medication prescribing: Specially trained pharmacists can prescribe medication(s) for a specific range of conditions (i.e. provide a prescription for a new medication).

- Outreach services: Pharmacists provide health care medication advice to communities with no pharmacy access.

- Immunisation providers: Specially trained pharmacists administer a variety of vaccinations. 


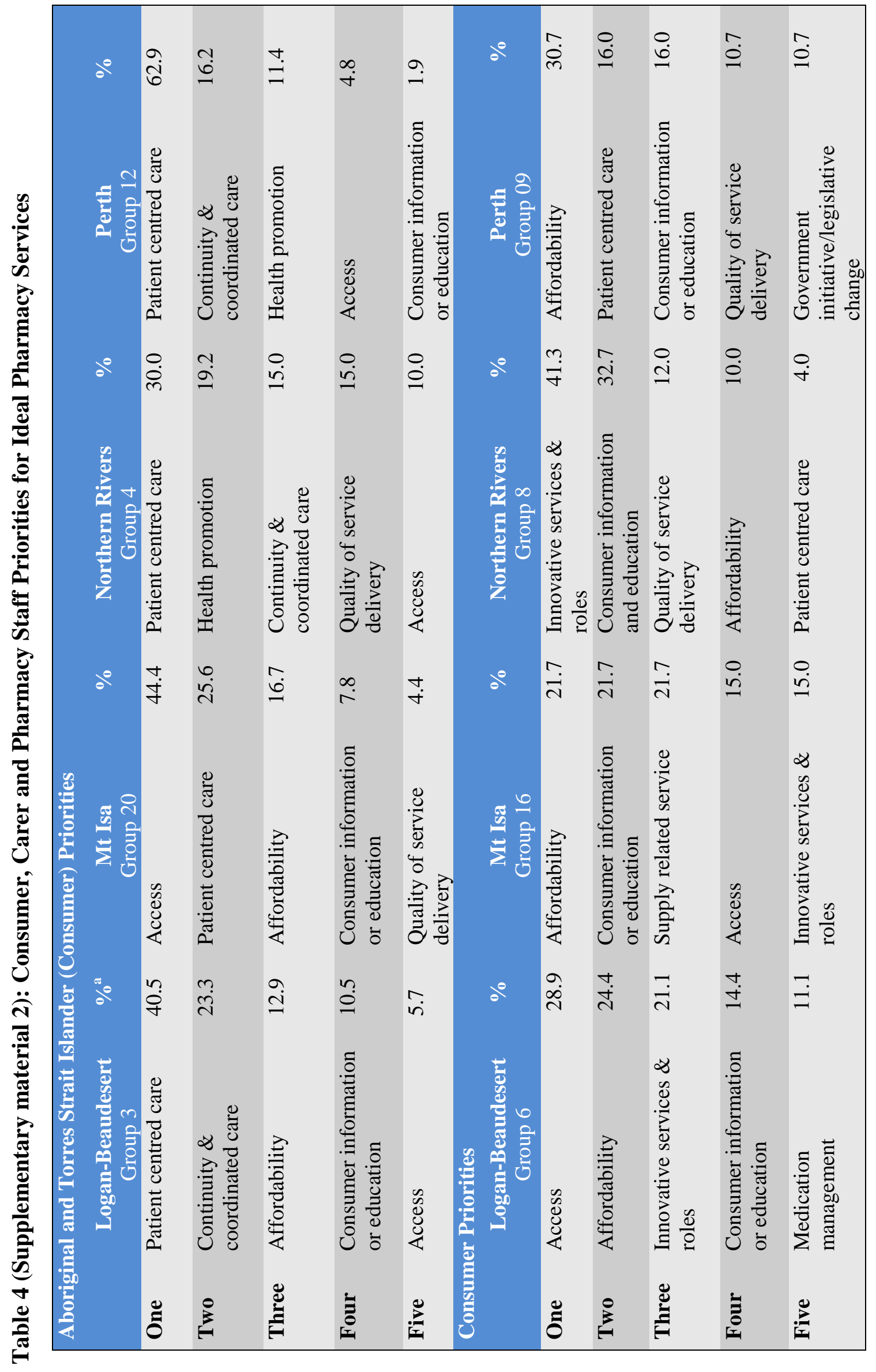




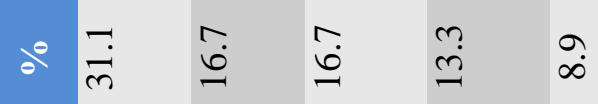

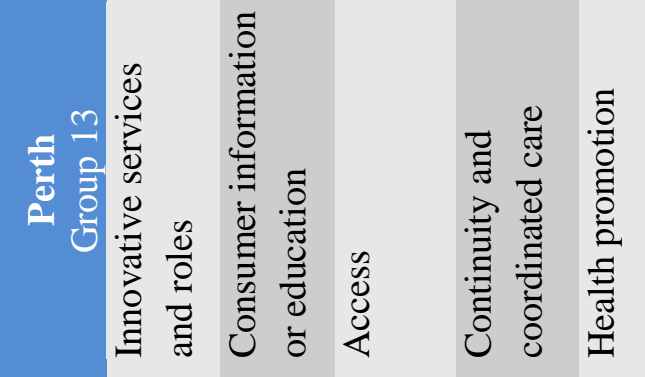

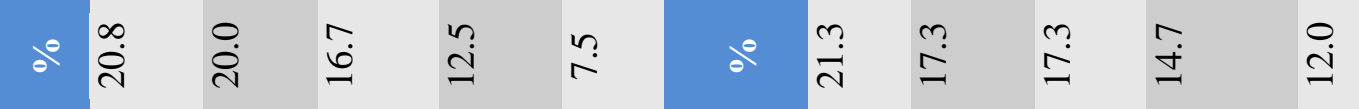

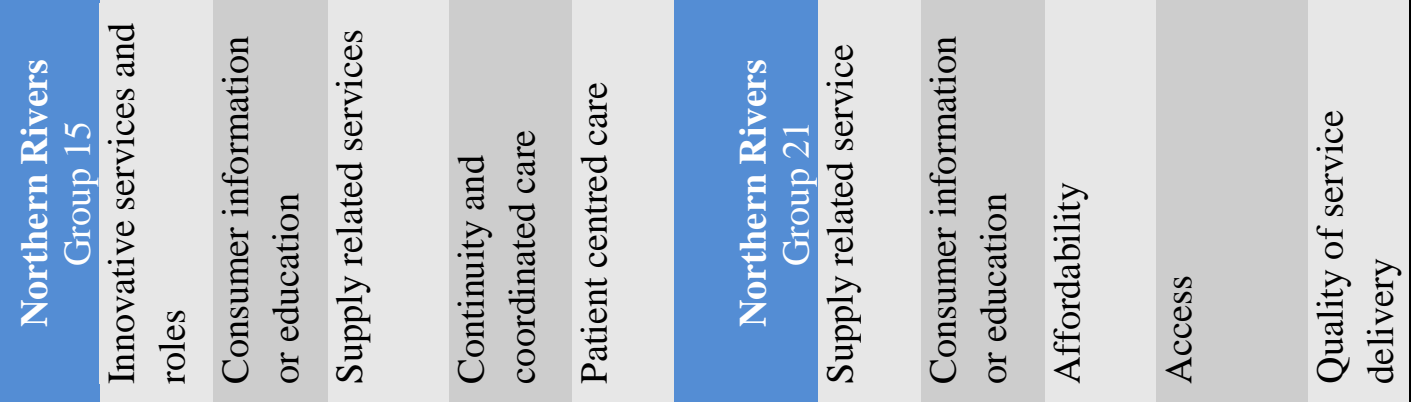

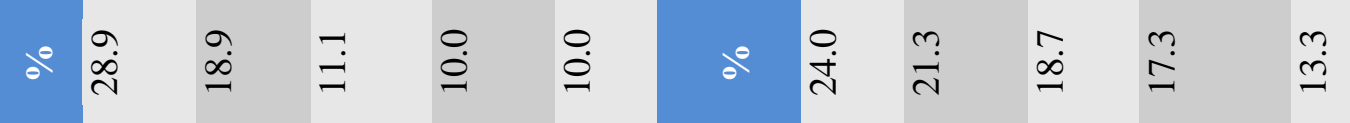

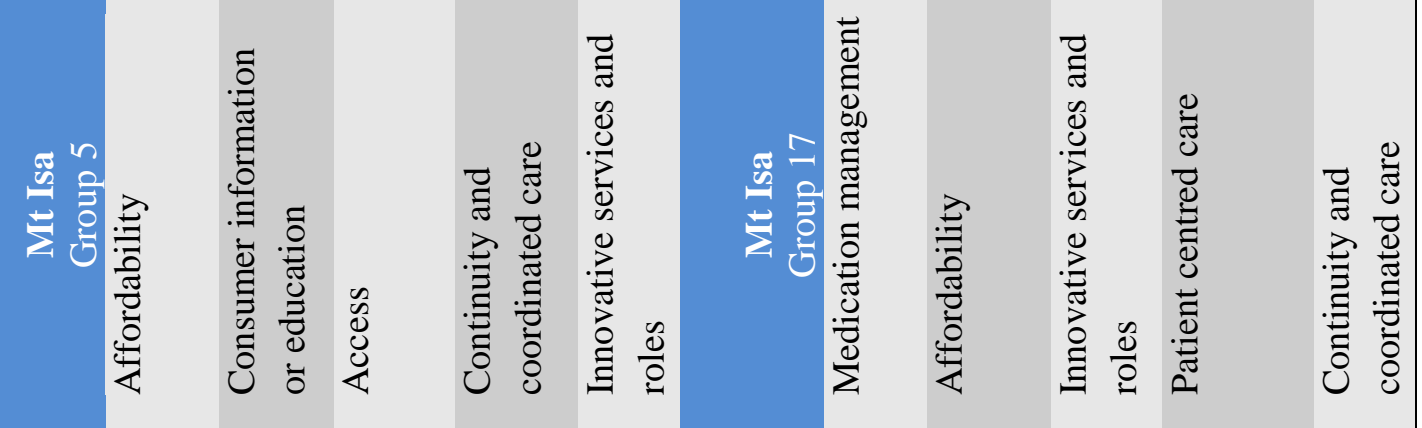

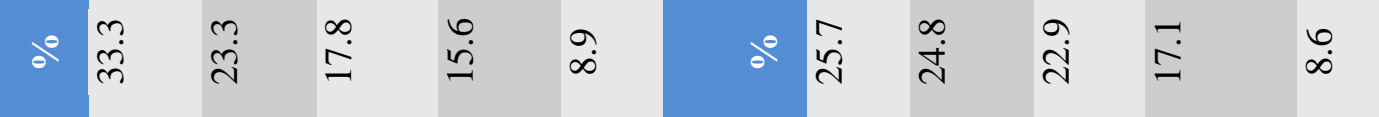

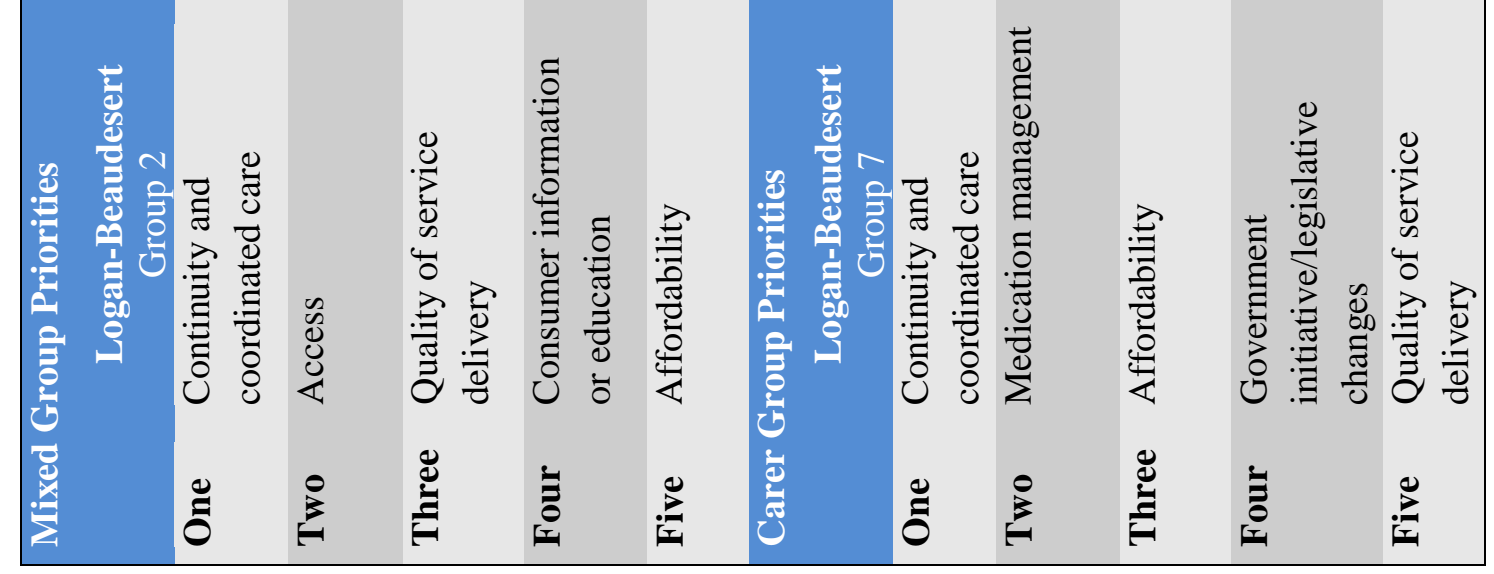




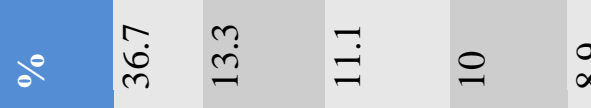

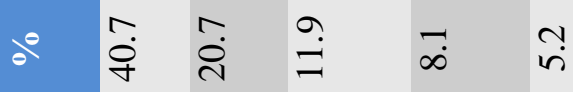

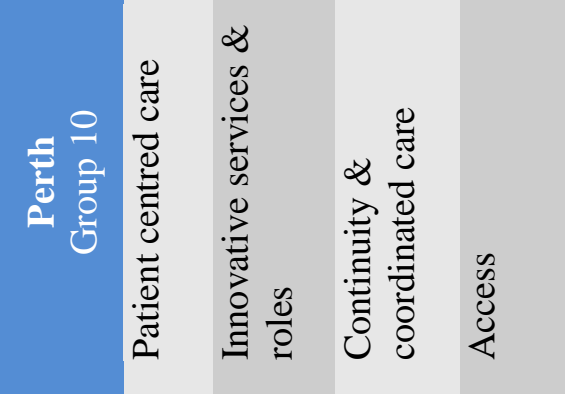

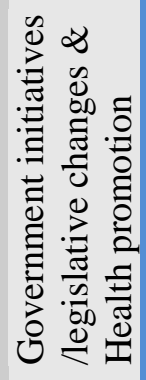

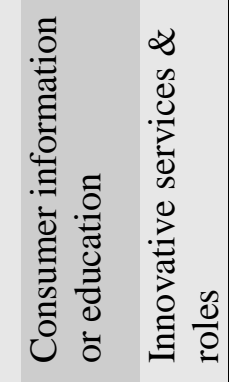

$\therefore$ 字

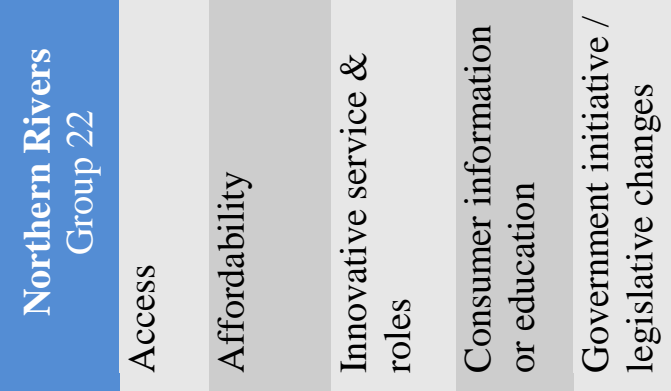

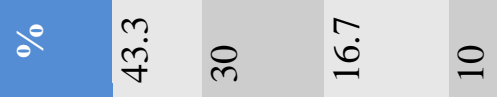

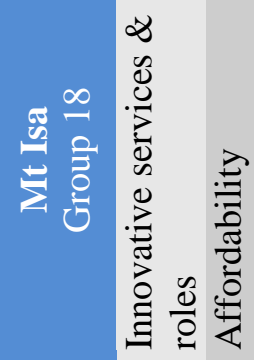

$\therefore$ 过

跣

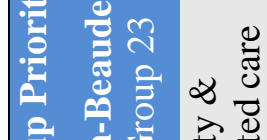

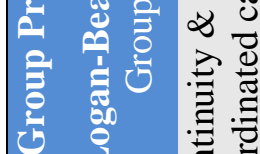

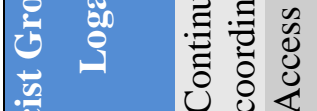

产

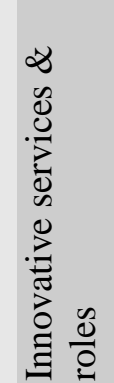

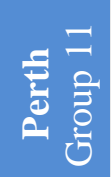

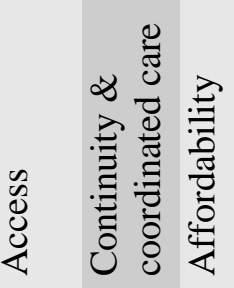

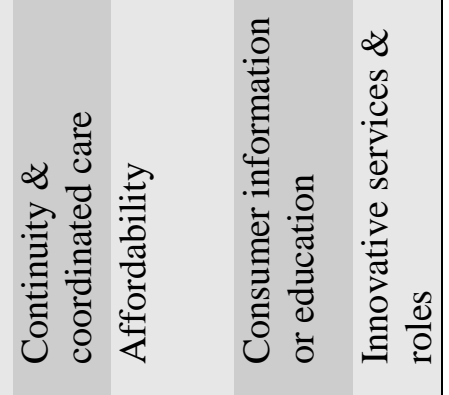

空 言

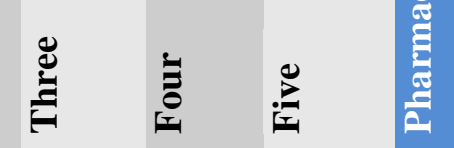

